Planning Practice \& Research, Vol. 13, No. 3, pp. 311-318, 1998

PRACTICE FORUM

\title{
The Potential for Planning an Industrial Cluster in Barre, Vermont: A Case of 'Hard-Rock' Resistance in the Granite Industry
}

\author{
ZENIA KOTVAL \& JOHN MULLIN
}

\section{Introduction}

Throughout the world, there has been considerable interest among economic planners concerning the creation of industrial clusters (Harrison, 1992, 1994). Efforts to stimulate, nurture and reinforce such clusters can be found in virtually all of the European nations, as well as in Japan, Korea, China and others (Malecki, 1991; Best, 1990). These efforts range from reinforcing the strengths of promising areas to stimulating the creation of totally new technologies (Castells \& Hall, 1994:. The identification of such clustering opportunities has become a critical element of national, state, regional and local planning activities. While there are many researchers who have focused on this topic, the Harvard Business School's Michael Porter has, arguably, been among the most effective in bringing the idea to working planners in both Europe and the US. His books and articles are widely read and analysed on both sides of the Atlantic and his ideas have become increasingly commonplace in mainstream planning for economic development. Of particular note is his work The Competitive Advantage of Nations (Porter, 1990). It remains to be seen, however, what happens when one attempts to implement Porter's principles through local planning.

A glimpse at what happened in Barre, Ver- mont between September 1994 and February 1995 could help answer that question. From September 1994, the authors were part of a team of scholars and practising planners, commissioned by the mayor and the city administration to conceptualise and prepare an economic development plan for the city. We worked with more than 100 local citizens, business leaders, community leaders and trade group representatives, to develop a plan that was largely based upon Porter's concepts.

This paper is a summary and analysis of the team's efforts. While one case study cannot conclusively determine anything, we hope to help clarify issues for similar economic development planning in other areas, and to contribute to research into the effectiveness of the Porter approach.

\section{The Concept of Industrial Clustering}

The notion of places, regions and even nations acquiring a comparative advantage due to certain industrial sectors clustering together is not new. The first theorist to examine comparative advantage was the eighteenth-century British economist David Ricardo, who studied the interrelations between growing capitalist markets, trade and regional or national patterns of econ- 
omic specialisation. In his conception, comparative advantage reflects the distribution of natural resources, climate, labour costs and differences in technology embodied in the production process. By the nineteenth century, neoclassical theory, emphasising the nature of demand and marginal costs and benefits, overshadowed classical theories centred around the labour theory of value. The neoclassical theory of comparative advantage includes more than one factor of production, i.e. capital as well as labour, and allows for the incorporation of demand, which Ricardo ignored (Walsh \& Gram, 1980).

Industrial clusters have been identified in Europe for generations-machining steel in Shefficld, textiles around Prato in Italy, chemicals along the Rhine, automobiles in the southwest German state of Baden-Wurtemberg, financial services in London and fashion design in Paris and Milan. The most notable clusters in the US are the electronics industry in the Route 128 area around Boston and the computer industry in California's Silicon Valley. Industrial clusters are emerging around medical devices (Minneapolis), biotechnology (San Diego, Worcester, Massachusetts), semiconductors (Austin) and software (Seattle/Portland).

Over the past decade, industrial policy experts have come to realise that a positive local environment is essential in developing global competitiveness. The interaction of peers. competitors, local universities and the local government is crucial for the long-term success of a firm. Scholars such as Annallec Saxenian (1994) agree that regions offer a competitive advantage to certain industrial clusters even as production and markets become increasingly global in nature. That proximity promotes repeated interaction and the mutual trust needed to sustain collaboration and enhance technological advancement. She argues, however, that spatial clustering alone does not create mutually beneficial interdependencics. There is a need for the complex of institutional and social relationships that connect the producers within a region's fragmented industrial structure. Bennett Harrison. in supporting the theory of clusters, argues that agglomerations of small- and medium-sized companies alone will not create significant success. There is a need for bigger firms to help upgrade the technical capabilities of their smaller suppliers.

After analysing components of effective in dustrial clusters in the US and abroad, Michae Porter developed the 'Diamond' model fol competitive industrial clusters. He identifiec four important aspects of economic activity tha are essential to a strong industrial base. The first relates to 'Factor Conditions'. It is here that the role of government and local institu. tions makes a difference. In order for loca' industry to succeed it must have the cooperation of local government. Government mus provide the water, sewer, highway and telecom. munications systems that enable companies ic compete. Government must also play a key role in training the workforce. For example, the plastics cluster in Fitchburg/Leominster. Mas. sachusetts has used the services of the University of Massachusetts (Amherst) for assistance in dealing with chemical compounds (poly. mers) and the University of Massachusetts (Lowell) for assistance on the shop floor.

The second element of Porter's model cen. tres on 'Demand Conditions'. These relate to : growing national (or local, but not international) demand and market for products. Porter's model requires more than increasing output based on having the cheapest product; i requires producers and buyers to work togethel to insure that price. quality and efficiencics are working cooperatively within a community When this occurs. there is a prospect for ar ever-increasing spirit of innovation throughou the industry. The local plastics industry ir Northern Worcester County (MA), for example has caught this spirit and moved from cheap plastic forks and spoons to high-tech 'sur screening' flight goggles for helicopter pilot: operating in desert conditions.

The third element eentres on 'Related anc Supporting Industrics. When foreign or inter national supplicrs have been globally tested they will inevitably help domestic end-produce companies improve their products and services Typically, they will have prospered in the world market by upgrading and improving pro duction techniques. processes and outputs They can then bring their entrepreneurial cul. ture to the domestic firms, where a highe: degree of competitiveness can emerge througt 


\section{Planning an Industrial Cluster}

mutually desired innovation, the transfer of information and a close working relationship. Porter maintains that there is a decided advantage when the suppliers and end producers are located in the same area: new ideas are tested more easily, informal learning results and news of the marketplace is shared. The integrating factor in Porter's Diamond is the fourth and final element: 'Firm Strategy, Structure and Rivalry'. Most companies do not define their strategies in a comprehensive manner. National industry leaders more commonly develop strategic plans based on the best analysis of world markets and trends, and the strengths and weaknesses of their competition. Small companies do not generally possess the economies of scale necessary to undertake such comprehensive strategic plans, however. Among smaller firms, strategic planning is often informal, inductive, reactive and too frequently lives only in the head of the chief executive officer.

Company structure is also an important component of Porter's fourth element. Experience shows that sole proprietorships with local roots tend to stay in their present locations even if market advantages can be found elsewhere. However, family-owned businesses change over time and the commitment to place diminishes as older generations retire. For planners and local officials interested in attracting and retaining businesses, corporate structure can be an important indicator of corporate stability. If lines of succession are unclear, if mergers are in the wind. or if the existing location's attractiveness wanes, then a company would appear to be in danger of relocating.

When rivalry among competitors, suppliers and customers exists there is continual improvement in product quality and an upgrading of labour. This is demonstrated in the more than 20 paper companies within 10 miles of Holyoke, Massachusetts ('The Paper City'), the 30 plastics companies within 10 miles of Leominster, Massachusetts ('The Pioneer Plastics (ity') and the hundreds of high-technology companies within 10 miles of Route 128 ('America's Technology Highway'). Local rivalry with mutual cooperation can result in an environment that has a strong competitive advantage, where change is viewed as an opportunity.
Organisations can help foster this spirit in the presence of company rivalries. A government 'laboratory' created such a spirit in the case of North Carolina's Research Triangle Park (Lugar \& Goldstein, 1992). The presence of a strong university can foster the same spirit. The spin-off companies from Stanford, Duke, MIT and the University of Texas, among others, provide examples of how this can happen (Dertouzos et al., 1989). A single university department can also help to stimulate this spirit, as in the case of the University of Massachusetts Polymer Studies Department. Another organisational structure, perhaps less widely recognised, is an industry network. Networks in the paper, plastics and granite industries have been quite effective. On the other hand, these networks can become overly protective and may focus on 'fighting the last war' rather than on fostering a spirit of healthy competition in the presence of industrial change.

Industrial clustering does not occur spontaneously. There must be companies within an industry that compete against each other, sophisticated suppliers that co-exist with local firms, companies whose strategic plans define their competition in a global framework, and a desire for improvement.

\section{Barre, Vermont, The Granite Capital}

The City of Barre, population 9482, is located in central Vermont between Montpelier and White River Junction, approximately 130 miles from Montreal, Canada. and 200 miles from Boston, Massachusetts (see Figure 1). First settled in 1769, it quickly became known for its vast quantities of granite. By the late nineteenth century, Barre had become known as the granite capital of the world. Although the claim is somewhat of an overstatement, the city sits on one of the most extensive granite deposits on the globe. Geologists estimate that the deposit is four miles long, two miles wide and ten miles deep.

The granite industry is the largest industrial sector in Barte. Therc are approximately 60 granite companies located in the Barre area. They employ approximately 1000 workers with an additional 400 workers supplying transportation, machinery or equipment repair services. 


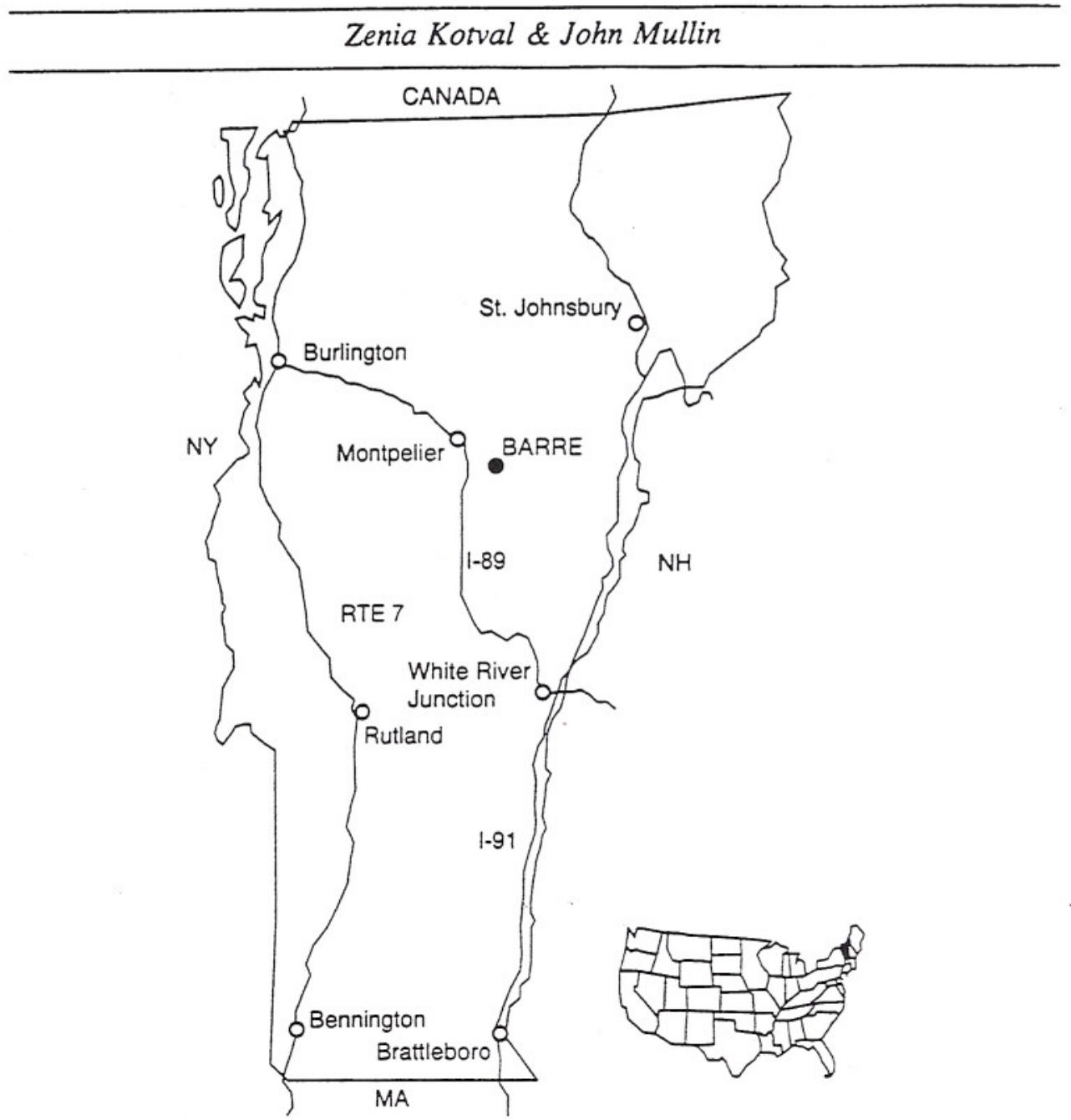

FIGURE 1. The location of Barte, Vermont.

The value of the products manufactured in Barre is estimated at approximately $\$ 100$ million per year. Approximately $47 \%$ of this represents the cost of materials, while $53 \%$ represents 'value added'. This relatively low percentage of value added refiects a reluctance by companies to invest in high technology or to take efforts to improve worker productivity.

The workforce is predominantly blue collar but very well paid by Vermont standards. Indeed, among manufacturing occupations, only the electrical workers in Vermont earn a higher hourly wage. Most of the workers own their own homes. Moreover, Barre has virtually no major crime and contains some of the most spectacular natural resources in the nation. There is little turnover in personnel in the granite industry, and sons have followed fathers into the quarries for generations. Based on citizen surveys and focus sessions, there are no obvious signs of a widespread desire among residents to broaden the city's industrial or occupational base.

\section{The State of Barre's Industry}

Changes in the granite industry are sending signs of foreboding over Barre and its industry. 
Although Barre's firms have carved out a strong market niche, granite sales are in a gradual decline and new quarries are being developed across the United States. In fact, by tons of rock cut and shipped, quarries in Elberton, Georgia now out-produce those found in Barre. The Barre industry has long specialised in rough-cut stone and grave markers. Approximately $90-95 \%$ of Barre's production is memorials and monuments.

There are clear signs that the granite industry as a whole has not adapted to changing market conditions. American builders are increasingly moving away from the use of granite as a building material; one reason for this may be that the industry has failed to standardise its cutting procedures like the brick, marble and concrete industries. The industry has also failed to 'add value' to its product. The marble industry has done far more to modernise than the granite industry and could serve as a model. Neither the Rock of Ages Company, the leading granite company in Barre, nor the Barre Granite Association (BGA), has made any noteworthy attempts to add value to their product.

The Rock of Ages Company is the prime example of the industry's shortcomings. Rock of Ages has six quarries in Barre alone and many more across the Northeast. Because the company is based in nearby New Hampshire, it functions as an absentee owner. In its constant quest to hold down costs and compete in the industry, Rock of Ages' business strategy makes it more like a multinational corporation than a home-grown firm. The company chooses its rock-cutting and selling sites, in part, with an eye toward achieving economies of scale. The company's freedom to choose where it cuts rock means that Rock of Ages does not need Barre as much as Barre needs Rock of Ages. To date, the company has served as a 'good citizen'. It participates in community events, is an active member of the BGA, and operates the Barre Granite Industries' Visitors' Centre. This supplements its inordinate impact on the local economy.

A key factor that could influence the furre of Barre's granite industry is increasing international competition. Under the World Trade Organisation (WTO), all tariffs on granite will eventually be removed. Already, granite from as far away as India is quarried, cut, finished polished and shipped to the US at a lower cost than a similar product can be supplied by Barre's companies. There are other nations, such as Italy and Spain, that also have a ready supply of the material and low extraction costs.

Considering the slipping domestic demand for granite, the powerful position of Rock of Ages within Barre's industry, and growing international competition, Barre's granite industry has cause for concern. This led officials and some industry leaders in Barre to consider how industrial clustering could help.

\section{The Potential for Planning an Industrial Cluster in Barre}

From the start of this project, the mayor and town manager saw the need for change far more clearly than did the granite industry. The local governmental leadership knew that the industry was not growing, wages were flat and Barre's market share was eroding. It clearly needed to stimulate change, but had little experience in planning for economic development. After looking at many approaches, the leadership felt quite comfortable in using the industrial clustering concept as a means of determining the state of Barre's industries, identifying weaknesses and providing a focus for potential municipal actions. The results are explained below.

Although the local government had come to recognise the need for change in its relations with the granite industry, its past record in providing Porter's Factor Conditions was mixed. Its role was primarily as a provider and guarantor of a social safety net for its citizens. In other words, economic planning and assistance were not of primary importance. The city had put together a 'Stone Trades' programme at the high school that regularly prepared 10 workers per year for the industry, but had no initiatives at the more significant university level. (Vermont's universities and colleges do not have a tradition of direct outreach.)

After reviewing the impact of their orientation with the consulting team. local government officials came to see that they could play an interventionary role in stimulating growth 
within their industrial base, and create a balance between providing a social safety net and supporting local companies. The shift in attitude was marked by modest but noteworthy initiatives. Zoning was quickly altered to meet companies' expansion plans, ideas were generated for the establishment of a granite museum in the city, and local officials helped write legislation to require the use of granite in all Vermont public buildings. The shift was also evident in the search for financial assistance. For years the Central Vermont Economic Development Corporation had a small revolving loan fund (RLF) sponsored by the US Economic Development Administration (EDA), but it had gone unnoticed by most Barre officials. After the study was completed, however, the leadership became active in obtaining more resources from the fund. They are also now determined to be active players in the EDArequired Overall Economic Development Programme (OEDP). Local government now at least considers the improvement of the granite business as being within its realm of responsibilities.

However, Barre's 'hard-rock' resistance to change is perhaps best illustrated by the unwillingness of the granite industry to provide Porter's second critical element of industrial clusters: meeting the level of demand for product and keeping up with product buyers' increasing sophistication. Barre's granite companies have been slow to innovate, reluctant to market new products, and unwilling to adjust to a changing industry. The skills, tools and market exist for Barre to become a cluster where the demands for improved products and greater competition stimulate 'value-added' product development. However, the BGA and the chief executive officers of many granite companies tend to see Barre's primary business as moving rock and cutting grave stones.

Suppliers to Barre's granite industry have made little effort to become globally competitive. Employers and business owners were surveyed by the consulting team, and wher asked about the influence of WTO or NAFTA they initially argued. like the industry itself, that these agreements will hurt Barre. When asked about the influence of the European Union or the need to follow international stan- dards, they argued that those developments are irrelevant.

Porter's capstone point, 'Firm Strategy Structure and Rivalry', points to another weak spot in Barre's industry: formal planning is rare. Companies' strategic plans are developed through informal processes, often determined by the gut instincts of company executives. In the absence of significant changes in the indus try, the firms on the whole have performed quite well. But if change is coming to the industry, as even local govemment officials have recognised, then more formal processes of strategic planning are needed to deal with the increasing complexity of the industry.

There is a great deal of rivalry in Barre's granite industry, but as the dominant firm in Barre and one of the leading granite companies in the US, Rock of Ages sets the tone. It has name recognition, a formal corporate structure, and a clearer sense of world trends than the smaller firms. Rock of Ages' hegemony perhaps provides the best explanation of the resistance in Barre to the adoption of a clustering strategy. Rock of Ages sees Barre as only a point of supply for the granite they need. The company strategy appears to be to extract the rock at the lowest possible cost, thereby maintaining their dominant position in the industry. An industrial cluster would necessarily require the formation of a new, more aggressive trade association (which Rock of Ages would pay a majority of the funds to support) and the entrance of granite competitors to the Barre region. Both of these developments would work against the company's goals. In addition, company management does not live in the city and therefore would not benefit personally from further economic development.

A number of the basic components for an industrial cluster are present in Barre. Barre's natural granite resources are by all measures immense and demand has been healthy. There are still impediments to creating a truly competitive environment. Barre's inability to develop its granite businesses into a special industrial cluster is due in large part to a rather feeble trade association, an increasingly outdated market orientation, a lack of commitment to 'value-added' products, a reluctance to compete in the world marketplace. and inadequate assistance from government. 


\section{Lessons Learned}

In trying to apply Porter's model to Barre, we identified several points that either receive inadequate attention in his approach or present interesting complications not explicitly addressed by Porter. These issues should be of interest to economic and industrial planners who are also interested in applying the model. The two main issues have to do with the role of government intervention and the role of the granite industry.

The role of governmental intervention is critical to producing Porter's Factor Conditions. Local government leadership can indeed become more interventionist, but that government intervention by itself is not enough to reverse the situation. After focusing on alternative approaches, the administration determined that it could help the local industrial base in several ways. First, it was to ensure that government did not serve as an impediment to growth. Thus, the public leadership made sure that the necessary water, sewer and other infrastructure capacity was in place. Second, the government officials were very sensitive to the industry's need for favourable tax policies. Local property taxes were kept low. Further, the city administrator, as well as Barre's state senators and state representatives, worked to keep workmen's compensation and unemployment insurance costs as low as possible. Third, the city was more than willing to use public funds to find new industrial sites so the granite companies could expand within the city boundaries. Finally, its education and banking institutions were oriented, as much as possible, to meet the needs of the industry.

In order to have a significant impact, the role of government must be clearly defined and carried out consistently over an extended period of time. Equally important, local government must know its limits. It cannot directly change federal policy, intervene in business operations or predict world events. In Barre, local government eventually came to recognise its role in nurturing the city's granite industry.

However, the necessary changes were not forthcoming in the granite industry. Not all companies strive for increased growth. If a company is making a high return on its invest- ments, has little debt, and can see a solid demand for its product, it may well continue to operate as it is. The presence of a competitive advantage will not, by itself, result in an automatic willingness to take on risk. As long as the owners are making a solid return on investment and the immediate future appears secure, they will continue to operate as they have in the past. There are many such companies in Barre.

Other important lessons of the Barre experience are noted below.

- The presence of the elements of an industrial cluster does not lead automatically to increased competitiveness. In the case of Barre, several elements were in place, but there was no catalyst to precipitate the necessary change in attitude within the granite industry.

- The dominance of one company in a local cluster contributes to a climate of uncertainty. There is never 'perfect equilibrium' in any industrial cluster.

- While the role of government is understood, industrial assistance programmes are still viewed with great scepticism. They are perceived as overly complicated, too intrusive and coming with too many strings attached. In the Barre case, the granite industry held to the old adage that government governs best when it governs least.

- Industrial associations can be instrumental in either promoting industrial clusters or impeding their development. They often reflect the wishes of the larger members of the organisation rather than the view of the majority. In order to promote clusters, associations need to lead their industries rather than follow them.

- Developing local points of pride is important. Boosterism, statues (Figurc 2), muscums and festivals can help to create a sense of pride and create $\mathrm{a}$ bond between the citizens and the industry. They may have little direct impact on the bottom line but can have a great impact on corporate and community morale.

- Industries need to establish better links with institutions of higher education. There appears to be little understanding in Barre's local government of how to bring together educational institutions to support an industrial cluster. Despite the best efforts of the 


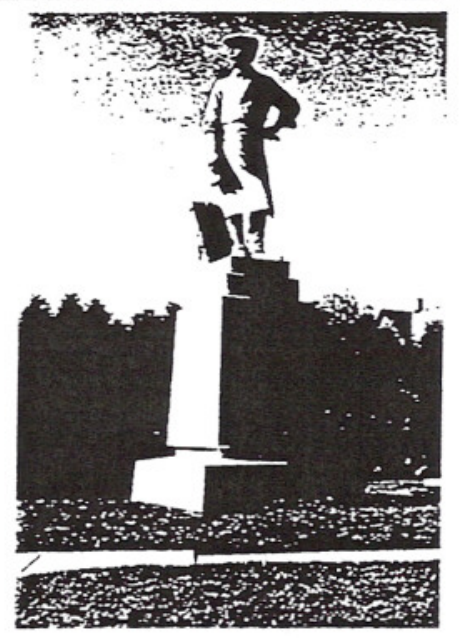

FIGLRE 2. The Stonecutter's Monument. Main Street. Barre. Vermont.

vocational school. the community college and the Private Industries Council (PIC), the results in Barre are unsatisfactory. The granite industry, like most other industries in the US, wants entry-level workers with good basic skills. The firms will train them in the particular company-established methods: the industry has a substantial lack of confidence in higher education.

- The creation of an industrial cluster in Barre requires a change in the industry's culture. Such a change has not occurred. The potential exists to move toward higher value-added businesses. such as from extraction to cutting to standardisation to speciality marketing to retail goods. Such changes. however. do not occur overnight. and the trip from a Barre quarry to a Manhattan designer's studio can be a long one indeed. A crucial lesson of the Barre experience is that industrial clusters have to evolve over time.

- There is no set formula for creating an industrial cluster. It must be grounded by an institution. natural resources, or a core company in order to emerge. But beyond those preconditions. the process of industrial cluster formation remains somewhat ill-defined.

We realise that a single case offers only a snapshot of a community and its industry at one moment in time. However. if the tindings are similar in other communities endeavouring to develop clusters. then there is reason to shift our focus decisively from the other factors in the Porter model toward the leadership environment.

\section{References}

Best, : M. H. (1990) The New Competition: Institutions of Industrial Restructuring (Cambridge. MA. Harvard University Press).

Castells, M. \& Haill. P. (1994) Technopoles of the World: The Making of 2lst Century Industrial Complexes (London. Routledge).

Dertouzos. M.. Lester. R. K. \& Solow. R. M. (1989) Made in America: Regaining the Competitive Edge (Cambridge. MA. MIT Press).

Harrison. B. (1992) Industrial districts: old wine in new bottles?. Regional Studies. 26(5). pp. 469483.

Harrison. B. (1994) Lean and Mean: The Changing Landscape of Corporate Power in the Age of Fleribilin (New York. Basic Books).

Lugar. M. \& Goldstein. H. A. (1992) Technology in the Garden (Chapel Hill. NC. University of North Carolina).

Malecki. E. J. (1991) Technology and Economic Development (.New York. John Wiley).

Porter. M. E. (1990) The Competitive Adrantage of Nations (New York. The Free Press).

Saxenian. A. (1994) Regional Adrantage: Culture and Competition in Silicon Vuller and Route 128 (Cambridge. M.A. Harvard Lniversity Press).

Walsh. V. \& Gram. H. (1980) Classical and Veoclas. sical Theories of General Equilibrium INew York. Oxford Lniversity Press). 